\title{
Interannual Variability in the Summer Season Onset, Length and End Dates Across the Iran (1948-2016)
}

\author{
Mahdi Sedaghat \\ Payame Noor University
}

Hamid Nazaripour ( $\nabla$ h.nazaripour@gep.us.ac.ir)

University of Sistan and Baluchestan https://orcid.org/0000-0002-9655-6091

\section{Research Article}

Keywords: climate variability, season change, temperature, tropopause pressure, Persian Gulf Trough

Posted Date: May 21st, 2021

DOl: https://doi.org/10.21203/rs.3.rs-283820/v1

License: (c) (i) This work is licensed under a Creative Commons Attribution 4.0 International License. Read Full License 


\title{
Interannual variability in the summer season onset, length and end dates across the Iran (1948-2016)
}

\author{
Mahdi Sedaghat ${ }^{1}$, Hamid Nazaripour ${ }^{* 2}$ \\ 1. Department of Geography, Payame Noor University, Tehran, Iran. \\ 2. Department of Physical Geography, University of Sistan and Baluchestan, Zahedan, Iran. \\ *Corresponding author: Hamid Nazaripour $\quad$ E-mail: h.nazaripour@gep.usb.ac.ir;
}

\begin{abstract}
It is very important to study the role of global warming on the variability of summer characteristics in arid and semi-arid climates such as Iran, because of its impact on natural and social systems. The aim of this study is to detect interannual variability in the onset, end and duration of the summer season in Iran. To achieve this goal, three indices are defined: physical, dynamic and synoptic. Daily data of the Earth's surface temperature $\left({ }^{\circ} \mathrm{C}\right)$, tropopause level pressure $(\mathrm{hPa})$ and geopotential height at 1000 hectopascals $(\mathrm{m})$ are the basis of physical, dynamic and synoptic indices, respectively. Data were extracted from the reanalysis databases for 1948 to 2016 in different domains. A three-variable dataset using regional mean values allowed researchers to determine the start date (onset) of the summer based on the following thresholds: Temperatures above $25{ }^{\circ} \mathrm{C}$ and duration of 10 days (physical index), tropopause level pressure less than $120 \mathrm{hPa}$ and duration of 10 days (dynamic index), geopotential height at $1000 \mathrm{hPa}$ less than $50 \mathrm{~m}$ and duration of 10 days (synoptic index). The opposite situation indicates the end of summer. The results showed that the start and end of summer based on physical, dynamic and synoptic indices are May 11 and September 21, June 4 and October 1, May 20 and September 15, respectively. The average length of summer is 134, 120 and 119 days, respectively. Statistically significant long-term trends have been observed for the start and end dates of the summer season. Seasonal variability has accelerated significantly since the late the twentieth century. In short, the summer season in Iran tends to start early and end late. As a result, summer lengths are longer in 80 percent of the years after 1981 compared with less than 50 percent from 1948 to 1981 .
\end{abstract}

Keywords: climate variability, season change, temperature, tropopause pressure, Persian Gulf Trough.

\section{Introduction}

Changes in the time and intensity of seasons can have a variety of effects on ecosystems and human society. For more than a century, we have realized that increasing the concentration of 
carbon dioxide in the atmosphere leads to an increase in surface temperature. But for just over two decades, changes in atmospheric $\mathrm{CO} 2$ levels have been shown to affect the timing of the annual temperature cycle_(Thomson, 2009). The change of seasons is directly related to global warming. The first discussion of the effect of global warming on seasonal cycle change was introduced by Thomson in 1995 (Mann \& Park, 1996). A slight change in temperature is enough to shift the seasons with the early onset of summer and the delay of the first frost until late autumn. Climate change is expected in the future to lead to shorter winters, early springs, longer summers and late autumns in the mid-range.

In determining the boundaries of the seasons, it is important to pay attention to their astronomical, meteorological and temperature definitions (Trenberth, 1983). It is clear that the change of seasons is more related to climate conditions than to astronomical calculations. To identify the characteristics of the seasons, three physical, dynamic and synoptic approaches have been proposed in the literature review. For example, Xavier et al (2007), using the difference between the average daily temperature range of 600 to $200 \mathrm{hPa}$, proposed a physical index to study the changes of the monsoon season in the tropics. Mofidi et al. (2010) emphasized this index and stated that the average summer in Iran lasts from June 7 to September 28 for 113 days and the number of summer days lasts 61 years, which has decreased significantly for 10 days later. Stine et al. (2009) also showed that the annual cycle of surface temperature in the subtropics in the period of 1954 to 2007 changed by 1.7 days per year compared to the early seasons.

Another approach to examine the quantity and quality of the beginning and end of the summer atmosphere has been a dynamic approach. This view is largely based on the theory that higher heat transfer in summer conditions leads to higher terpopause(Gabriel et al, 1999). Therefore, deep convection in the intercontinental convergence belt or on the intermediate extensions of the continents in the summer continuously solves upward terpopause and deepens the troposphere. During the monsoon summer, terpopause sometimes occurs above $18 \mathrm{~km}$ (Mohanakumar, 2008). From low to high latitudes, the height of the terpopause decreases rapidly at the location of the subtropical jet and the polar front. Especially when the jet is strong 
and the front is severe at low levels, its height suddenly drops across the jet stream (Hirschberg and Fritsch, 1991).

Goldreich and Chermoni (2006) used tropopause altitudes above $16 \mathrm{~km}$ for at least ten consecutive days on synoptic graphs as a measure of summer length change in the Middle East. The results of significant trends showed that summer starts earlier and ends later, and the number of summer days has increased during the study period. With this approach, the structure of large-scale air circulation and summer behavior of subtropical jet in the Middle East over a period of 30 years (1981-2010) have been studied to determine the beginning of summer in Iran (Gholipour et al. 2017). In this study, the daily behavior of the subtropical jet, including the flow intensity and the amount of northward movement, has been investigated. The results show significant deviations in the early beginning of summer in the Middle East.

The third method for identifying seasons is the synoptic approach. A review of climatic records shows that in each season, there are specific synoptic systems in an area (Lamb, 1972). In each region, atmospheric researchers identify the dominant synoptic systems of each season. For example, in the eastern Mediterranean, the predominant summer synoptic system is the Persian trough (Ziv et al, 2004). The Persian trough is formed only a few days after the beginning of the monsoon cycle and the flow penetration of its into the Persian Gulf at the level of 850 hectopascals (1500 meters). Summer in the region ends in mid-September with the sudden disappearance of the Persian trough (Bitan \& Sa'aroni, 1992). The Persian trough lasts for three months, starting on June 10 on average, and the upper cell reaches its highest point on June 25 (Elbashan, 1967).

A new season definition in the eastern Mediterranean based on the daily classification of synoptic systems showed the timing and duration of cold, hot,dry and rainy seasons and transition seasons (Alpert et al, 2004). According to the synoptic definition presented in this work, each summer and winter seasons last about 4 months (three months and 23 days). Synopticaly, they defined the beginning of summer with the conquest of the Persian trough over the region and estimated its length from May 23 to September 22(Goldreich, 2012). 
Determining the boundaries of the seasons is important for organizing agricultural activities, tourism, transportation planning, etc. However, identifying the start, continuation, and end dates of different seasons, especially in the Middle East with diverse marine, desert, steppe, and mountain climatic regimes, has become a serious problem (Alpert et al, 2004). On the other hand, the effect of climate change on reducing the length of the cold period of the year (autumn and winter) in the Iranian plateau to lack of rainfall and increasing the length of the warm period of the year (spring and summer) to the growth of more invasive species, pests, drought, evaporation and heat stress ended. In relation to Iran, the research of Babaian et al. (2015) shows that the situation is more worrying than it is. It is predicted that the average annual temperature in Iran by 2100 , according to Scenario A2, will increase by 4.5 to 5.5 degrees Celsius, and according to Scenario B2, by 3 to 4 degrees Celsius. Assuming that global warming in recent decades has led to an upward trend in the length of the summer barley period and a significant increase in its intensity, researchers have studied interannual variability of the onset, end and length of the summer season in Iran.

\section{Data and Method}

\section{Data}

In this study, the summer season in the territory of Iran has been studied from three aspects. Daily data of the Earth's surface temperature (Celsius), tropopause level pressure (hectopascals) and geopotential height at 1000 hectopascals (meters) are the basis of physical, dynamic and synoptic indices, respectively. Data were extracted from the reanalysis databases for 1948 to 2016 in different domains (Figure 1).

There are a lot of discussions about the determination and number of seasons. There are four seasons based on meteorological and astronomical criteria (Tveito et al. 2000; Ruosteenoja et al. 2010). Today, the effect of global warming on the seasonal structure of climate is becoming a common field in climate studies. Meanwhile, the study of variability of summer characteristics in arid and semi-arid climates such as Iran is very important due to its impact on natural and social systems. Determining the characteristics of each season, including the onset, lenghth, and end, has always remained a challenge. In many studies, the time of the beginning of summer is defined based on temperature thresholds (Zhang et al. 2005). In this 
study, a temperature threshold of $25^{\circ} \mathrm{C}$ and duration of 10 days are considered as the beginning of summer (Table 1). The threshold of dynamic and synoptic parameters has been determined experimentally. The decrease in the mean values of terpopausal pressure below the threshold of $120 \mathrm{hPa}$ indicates the northward displacement of the subtropical atmosphere from the Iranian plateau and the establishment of the summer atmosphere. This shift, followed by a decrease in terpopause pressure, often occurs over a short period of one to three days. Therefore, monitoring the pressure drop of this layer below $120 \mathrm{hPa}$ as the threshold to study the time of onset, end and length of summer in the form of dynamic index was considered by researchers. The synoptic index considers the beginning of summer to coincide with the establishment of the Persian Gulf trough with the southeast-northwest axis on the Persian Gulf to Turkey (Figure 2). This system, in the form of a branch of low-rise located on the Indian subcontinent, by forming a lateral low-rise core on the southern shores of the Persian Gulf and following the southeast-northwest length of the Persian Gulf with the Cyclone flow, develops a low-pressure tongue in the form of a trough to the coast of Antalya in Turkey (Sa'aroni, 1984; Alpert et al, 1990). Considering the prominent role of Persian Gulf trough formation and the beginning of summer in the Middle East, researchers designed an indicator to estimate the beginning and end of the penetration of this low-pressure tongue and study the trend of changes in summer length in the region. In the southern shores of the Persian Gulf, by reducing the height of the geopotential potential below the threshold of 50 meters, the formation of the Persian name and the expansion of its languages are provided. At the peak of the activity of this system, its central height value reaches -50 . Therefore, the 50-meter threshold was determined as the synoptic index on the average long-term regions of geopotential elevation data at $1000 \mathrm{hPa}$ in the Persian Gulf. The set thresholds of the indicators to determine the onset, end and continuation of the summer season in the region are shown in Table (1). The passage of daily data values explaining indicators from the threshold and their 10-day duration indicates the onset and the opposite situation indicates the end of the summer.Applying a conditional function based on the threshold with duration of 10 days on the data, the length of the summer season is calculated based on each of the indicators in each year. 
148

149

150

151

152

153

154

155

156

157

158

159

160

161

162

163

164

165

166

167

168

169

170

\section{Methodology}

Annual variability of the onset, end, and length of the summer season related to each of the aspects was evaluated using Ljung-Box parametric test. The Ljung-Box test is an improved form of the Portmanteau test that is used to check the independence of observations in time series. The Portmanteau test for the first time was offered by Box-Pierce (1970) and its statistics are as follows:

$$
\mathcal{Q}=n \sum_{i=1}^{m} r_{i}^{2} \sim x_{m}^{2}
$$

Where

$n$ is the number of observations, $m$ is the number of lags included in the test (generally between N/15 and N/10) and $r_{i}$ is the $i$ th autocorrelation coefficient between $x_{t}$ and $x_{t+1}$; that is,

$$
r_{i}=\operatorname{corr}\left(x_{t}, x_{t+1}\right)=\sum_{t=1}^{n-i}\left(x_{t}-\bar{x}\right)\left(x_{t}-\bar{x}\right)\left(x_{t+i}-\bar{x}\right) / \sum_{t=1}^{n}\left(x_{t}-\bar{x}\right)^{2}
$$

The three rules proposed for the calculation of $m$ are as follows, (1) $m=n / 4$, (2) $m=\sqrt{n}+10$ and (3) $m=\ln (n)$. Simulation studies have shown that $m \approx \ln (n)$ leads to the best power for the test. In the portmanteau test, the independence hypothesis is written as $H_{0}=r_{1}=r_{2}=\cdots=r_{m}=0$ versus $H_{1}=$ $r_{i} \neq 0$ for a number of $i \in\{1,2, \ldots, m\}$.

Ljung and Box (1978) proposed a modified version of the portmanteau test as follows:

$$
\mathcal{Q}^{*}=n(n+2) \sum_{i=1}^{m} \frac{r_{i}^{2}}{n-1} \sim x_{m}^{2}
$$

Here, the independence hypothesis is not confirmed if $\left|Q^{*}\right| \geq x_{m}^{2}$. In other words, if the probability value of the test statistic is less than 0.05 , the independence hypothesis is not confirmed. If the $H_{0}$ is rejected, the Pearson's correlation coefficient test is used to determine trend characteristics. Pearson's correlation coefficient is denoted by $r$ symbol and is obtained from the following equation.

$$
r=\frac{S_{x y}}{\sqrt{S_{x x} S_{y y}}}=\frac{n \sum x y-\sum x \sum y}{\sqrt{\left[n \sum x^{2}-\left(\sum x\right)^{2} \operatorname{In} \sum y^{2}-\left(\sum y\right)^{2}\right]}}
$$

The significance of the $r$ is displayed with $\mathrm{T}$ and is calculated based on the following statistics:

$$
T=\frac{r \sqrt{n-2}}{\sqrt{1-r^{2}}}
$$


171

The following statistic is used to test the hypothesis in Pearson's correlation coefficient,

173

174

175

176

177

178

179

180

181

182

183

184

185

186

187

188

189

190

191

192

193

194

195

196

197

$$
Z=\frac{X-\mu_{X}}{\sigma_{X}} \sim Z_{1-\frac{\alpha}{2}}
$$

If $|Z| \geq Z_{1-\frac{\alpha}{2}}$ is holding, then the null hypothesis is rejected, otherwise $\left(|Z|<Z_{1-\frac{\alpha}{2}}\right)$ the null hypothesis is confirmed.

\section{Results and Discussion}

Applying the conditional function on the data of average temperature zones in the territory of Iran showed that according to the physical index, on average, the beginning and end of summer are May 11 and September 21, respectively, and its duration is 134 days (about four months) (Table 2). While the duration of the summer season in terms of dynamic index is equal to 120 days. The dynamic index shows that in the long run, the average summer starts on June 4th and ends on October 1st. Comparing the beginning and end of the summer season from the point of view of dynamic index in relation to physical index showed that this season starts both 25 days later and ends 11 days later each year. The length of the summer season is 119 days in terms of the synoptic index.

On average, according to the Synoptic Index, summer begins on May 20 and ends on September 15. Comparison of the beginning and end time of the summer season in terms of synoptic with the previous two indicators shows that this season starts and ends 9 days later and 6 days earlier than the physical index. However, compared to the dynamic index, the summer season starts 16 days earlier and ends 17 days earlier.

For comparative study, the study period was divided into two periods: 1948-1981 and 19822015. Representation of the average data of temperature zones (physical index) showed that in the second climatic period (1981-2015), the length of the summer season has increased. This increase from 129 days to 141 days was associated with 5 days beginning earlier and 7 days ending later in the second climatic period than in the first climatic period (Figure 3). Unlike the physical index, the dissociation and plotting of fluctuations in the regional mean data of the terpopause pressure (dynamic index) showed that the length of the summer in the second climate period (1982-2015) has been reduced compared to the first climate period (1981-1948). 
This decrease has been recorded from 128 days in the first climatic period to 117 days in the second climatic period with 6 days beginning later and 7 days ending earlier (Figure 4).

200

201

202

203

204

205

206

207

208

209

210

211

212

213

214

215

216

217

218

219

220

221

222

223

224

225

226

Also, the study of the fluctuations of the regional mean pressure data at $1000 \mathrm{hPa}$ in the study area during two separate climatic periods showed that from the point of view of the synoptic index, the length of summer has decreased in the second climatic period (1982-2015) compared to the first period (1981-1948) as the dynamic index. The reduction of the summer length from 122 days in the first climatic period to 115 days in the second climatic period with 3 days beginning later and 5 days ending earlier (Figure 5).

Examination of the variability of summer time characteristics by applying Ljung-Box test on the time series of beginning, end and continuation of summer obtained from physical, dynamic and synoptic indicators showed that the time series of all three indicators have a trend (Table 3). However, time series of summer, end and duration values based on physical index and summer continuity values based on synoptic index have a very meaningful process. However, the time series of the values of the beginning and end of the summer season based on two dynamic and synoptic indices along with the values of the continuation of the summer season based on the dynamic index do not have a significant trend. Time series were extracted to determine the significant type and level of trends in Pearson correlation coefficients (Table 4).

Execution of Pearson correlation test on the time series of beginning, end and continuation of the summer season based on physical, dynamic and synoptic indices showed that only the trend of physical index values are significant (Table 4). So that the values of the time series of the beginning of the summer season decreased due to the early onset of that season with a correlation coefficient of -0.25 had a significant decreasing trend at the level of 0.001 . Also, the values of the end time series and the continuation of the summer season based on the physical index with a correlation coefficient of 0.29 and 0.34 , respectively, had significant upward trends at 0.001 . Based on the statistics of the time characteristics of the beginning, end and continuation of the summer season obtained from the physical index (Table 4), it is inferred that the length of the summer period has increased during the study period. Unlike the physical index, the values of the time series of the beginning of the summer season based on both dynamic and synoptic indices have had positive increasing trends. Although the values of the 
227

time series of the end and continuation of the summer season based on both dynamic and synoptic indices have negative decreasing trends, but none of the relevant trends have reached the required level and do not show much change in summer time characteristics.

\section{Suumery and Conclusion}

The present study has designed three indicators of physical, dynamic and synoptic with the aim of investigating the variability of annual summer characteristics in Iran. These indices were extracted using daily temperature data at a height of $2 \mathrm{~m}$ above the ground, terpopause elevation pressure and geopotential height of $1000 \mathrm{hPa}$, respectively. Applying the conditional function of 10-day length, the threshold values of the designed indicators were estimated on the average of the regions of the variables, onset time, end time and continuity. The results showed that on average, the length of the summer season is based on 134 days on the physical index, 120 days on the dynamic index and 119 days on the synoptic index. The division of the research period into two climatic periods for a comparative study of the length of summer in the region showed that physically (temperature) in the last three decades, summer seasons tend to start earlier and end later. Findings related to the other two indicators were the opposite. So that the length of the summer season during the last three decades in terms of dynamic and synoptic index have shown a later onset and an earlier end. Findings of Ljung-Box test showed that all time series of beginning, end and continuation of the summer season (derived from physical, dynamic and synoptic indicators) had a trend. According to the model statistics, only the increasing trend of the time series of the physical index is significant enough. The results of the Pearson test showed that based on the physical index, the values of the beginning, end and continuation of the summer season, with correlation coefficients of $-0.25,0.29$ and 0.34 , respectively, have quite significant trends. Therefore, in the 68 years studied, in terms of temperature (physical index) has been added to the length of summer in Iran. These results are in contrast to Mofidi et al.'s (2010) study, which estimated a 10-day reduction in the number of summer days over a 60-year period. In contrast, testing the hypotheses on the other two dynamic and synoptic indices showed a decreasing trend in the end and continuity of the summer season, while none of the decreasing trends during the summer season resulting from 
these two indices was significant. These results are consistent with previous research (including; Mofidi et al., 2010 and Gholipour et al., 2017).

Due to the limitations of terpopause height data, the researchers were unable to use this data to represent the dynamic atmosphere of the region. However, studies by Goldreich and Chermoni (Goldreich and Chermoni, 2006) indicate the effectiveness of the data in studying the summer atmosphere in the Middle East. Therefore, further studies based on criteria such as the height of tropopause are suggested by researchers for further studies.

\section{Conflict of interest}

The authors declare that they have no known competing financial interests or personal relationships that could have appeared to influence the work reported in this paper.

\section{Author's contribution}

The authors declare that the manuscript has been read and approved by all named authors and that there are no other persons who satisfied the criteria for authorship but are not listed. We further confirm that the order of authors listed in the manuscript has been approved by all of us.

\section{Funding statement}

The authors received no financial support for the research, authorship, and publication of this article.

\section{Availability of data and material}

The datasets used during the current study are available in the Geospatial Interactive Online Visualization and Analysis Infrastructure (Giovanni), Giovanni and European Centre for Medium-Range Weather Forecasts (ECMWF) database in the following links

\section{https://giovanni.gsfc.nasa.gov/giovanni/}

\section{https://www.ecmwf.int/en/forecasts/datasets/browse-reanalysis-datasets}

and the datasets analyzed during the current study are available from the corresponding author on reasonable request.

\section{Code availability}

Code for data analysis has been developed in MATLAB software and available from the corresponding author on reasonable request. 


\section{Ethics approval}

286

287

288

289

290

291

292

293

294

295

296

297

298

299

300

301

302

303

304

305

306

307

308

309

310

311

312

313

314

315

316

317

We declare that this submission follows the policies of the journal as outlined in the guide for authors and in the ethical statement.

\section{Consent to participate}

All authors contributed to the study. Data collection was performed by Mahdi Sedaghat. Data analysis was performed by Hamid Nazaripour. The first draft of the manuscripts was written by Mahdi Sedaghat. All authors checked and commented on the previous version, read and approved the final manuscript.

\section{Consent for publication}

We confirm that we have given due consideration to the protection of intellectual property associated with this work and that there are no impediments to publication, including the timing of publication, with respect to intellectual property. In so doing we confirm that we have followed the regulations of our institutions concerning intellectual property.

We understand that the Corresponding Author is the sole contact for the Editorial process. He is responsible for communicating with the other authors about progress, submissions of revisions, and final approval of proofs. We confirm that we have provided a current, correct email address which is accessible by the Corresponding Author.

\section{Referrences}

Alpert, P., Abramsky, R., \& Neeman, B. U. (1990). The prevailing summer synoptic system in Israelsubtropical high, not Persian trough. Isr. J. Earth Sci, 39(2-4), 93-102.

Alpert, P., Osetinsky, I., Ziv, B., \& Shafir, H. (2004). A new seasons definition based on classified daily synoptic systems: an example for the eastern Mediterranean. International Journal of Climatology: A Journal of the Royal Meteorological Society, 24(8), 1013-1021.

Babaeian, I., Modirian, R., Karimian, M., \& Zarghami, M. (2015). Simulation of climate change in Iran during 2071-2100 using PRECIS regional climate modelling system. Desert, 20(2), 123-134. https:// 10.22059/jdesert.2015.56476.

Bitan, A., \& Sa'Aroni, H. (1992). The horizontal and vertical extension of the Persian Gulf pressure trough. International Journal of Climatology, 12(7), 733-747. https://doi.org/10.1002/joc.3370120706.

Box, G. E., \& Pierce, D. A. (1970). Distribution of residual autocorrelations in autoregressiveintegrated moving average time series models. Journal of the American statistical Association, 65(332), 1509-1526.

Elbashan, D. (1967) Summer meteorology in Israel. Meteorologia BeIsrael, 4, 3-8. 
Gabriel, A., Schmitz, G., \& Geprägs, R. (1999). The tropopause in a 2D circulation model. Journal of the atmospheric sciences, 56(23), 4059-4068.

Gholipour, J., Sanayinejad, S. H., Mofidi, A., \& Alizadeh, A. (2017). Determining the Beginning of Summer Season in Iran on the Basis of Abrupt Northward Jump of the Subtropical Jet Stream over the Middle East. Journal of Geography and Environmental Hazards, 5(4), 57-71.

Goldreich, Y \& Chermoni, Z. (2006). The changes in the summer season length in the Middle East, Conference of Climate Change in the Middle East.

Goldreich, Y. (2012). The climate of Israel: observation, research and application. Springer Science $\&$ Business Media.

Hirschberg, P. A., \& Fritsch, J. M. (1991). Tropopause undulations and the development of extratropical cyclones. Part II: Diagnostic analysis and conceptual model. Monthly weather review, $119(2), 518-550$.

Lamb, H. H. (1972). British Isles weather types and a register of the daily sequence of circulation patterns 1861-1971.

Ljung, G. M., \& Box, G. E. (1978). On a measure of lack of fit in time series models. Biometrika, 65(2), 297-303.

Mann, M. E., \& Park, J. (1996). Greenhouse warming and changes in the seasonal cycle of temperature: Model versus observations. Geophysical Research Letters, 23(10), 1111-1114.

Mofidi. A, Zarrin. A, Fasullo. J, (2010) Summer Circulation in the Upper Atmosphere on Southwest Asia and it's Variations during the last half century, 4th Regional Climate Change Conference, Tehran, 21 to 22 December, pp 149-160.

Mohanakumar, K. (2008). Stratosphere troposphere interactions: an introduction. Springer Science $\&$ Business Media.

Ruosteenoja, K., Räisänen, J., \& Pirinen, P. (2011). Projected changes in thermal seasons and the growing season in Finland. International Journal of Climatology, 31(10), 1473-1487.

Sa'aroni, H. (1984). The Extension of the Persian Trough and its Characteristics in the Middle East (Doctoral dissertation, MA Thesis, Dept. of Geography, Tel Aviv University, 398p).

Saaroni, H., \& Ziv, B. (2000). Summer rain episodes in a Mediterranean climate, the case of Israel: climatological-dynamical analysis. International Journal of Climatology: A Journal of the Royal Meteorological Society, 20(2), 191-209.

Stine, A. R., Huybers, P., \& Fung, I. Y. (2009). Changes in the phase of the annual cycle of surface temperature. Nature, 457(7228), 435-440.

Thomson, D. J. (2009). Shifts in season. Nature, 457(7228), 391-392.

Trenberth, K. E. (1983). What are the seasons?. Bulletin of the American Meteorological Society, 64(11), 1276-1282. 
Tveito, O. E., Førland, E., Heino, R., Hanssen-Bauer, I., Alexandersson, H., Dahlström, B., ... \& Westman, Y. (2000). Nordic temperature maps. DNMI report, 9(00).

Xavier, P. K., Marzin, C., \& Goswami, B. N. (2007). An objective definition of the Indian summer monsoon season and a new perspective on the ENSO-monsoon relationship. Quarterly Journal of the Royal Meteorological Society: A journal of the atmospheric sciences, applied meteorology and physical oceanography, 133(624), 749-764.

Zhang, X., Hegerl, G., Zwiers, F. W., \& Kenyon, J. (2005). Avoiding inhomogeneity in percentilebased indices of temperature extremes. Journal of Climate, 18(11), 1641-1651.

Ziv, B., Saaroni, H., \& Alpert, P. (2004). The factors governing the summer regime of the eastern Mediterranean. International Journal of Climatology: A Journal of the Royal Meteorological Society, 24(14), 1859-1871.

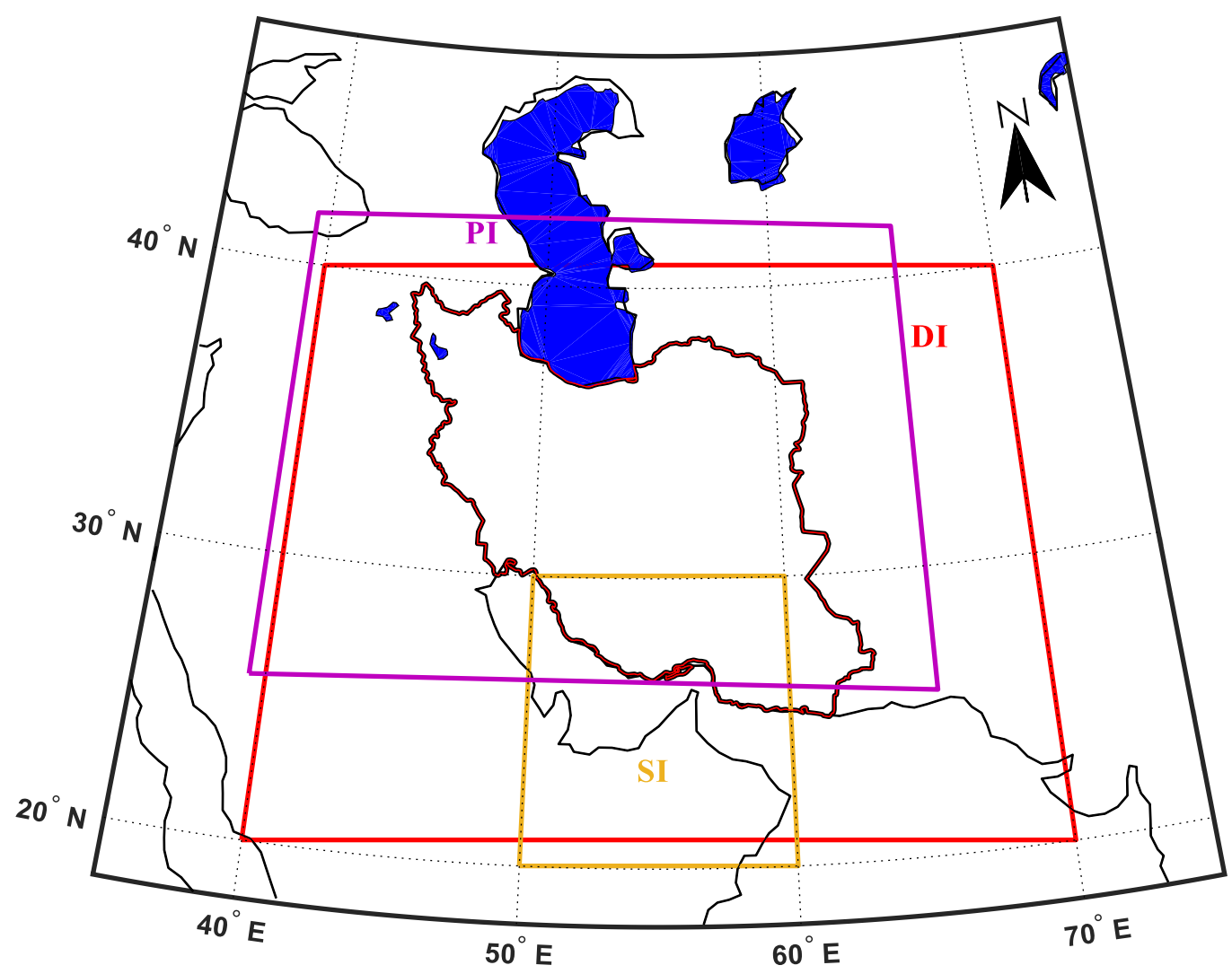

Figure 1. Geographical domains of different indicators for determining the temporal characteristics of the summer season, PI (Physical), DI (Dynamic) and SI (Synoptic). 


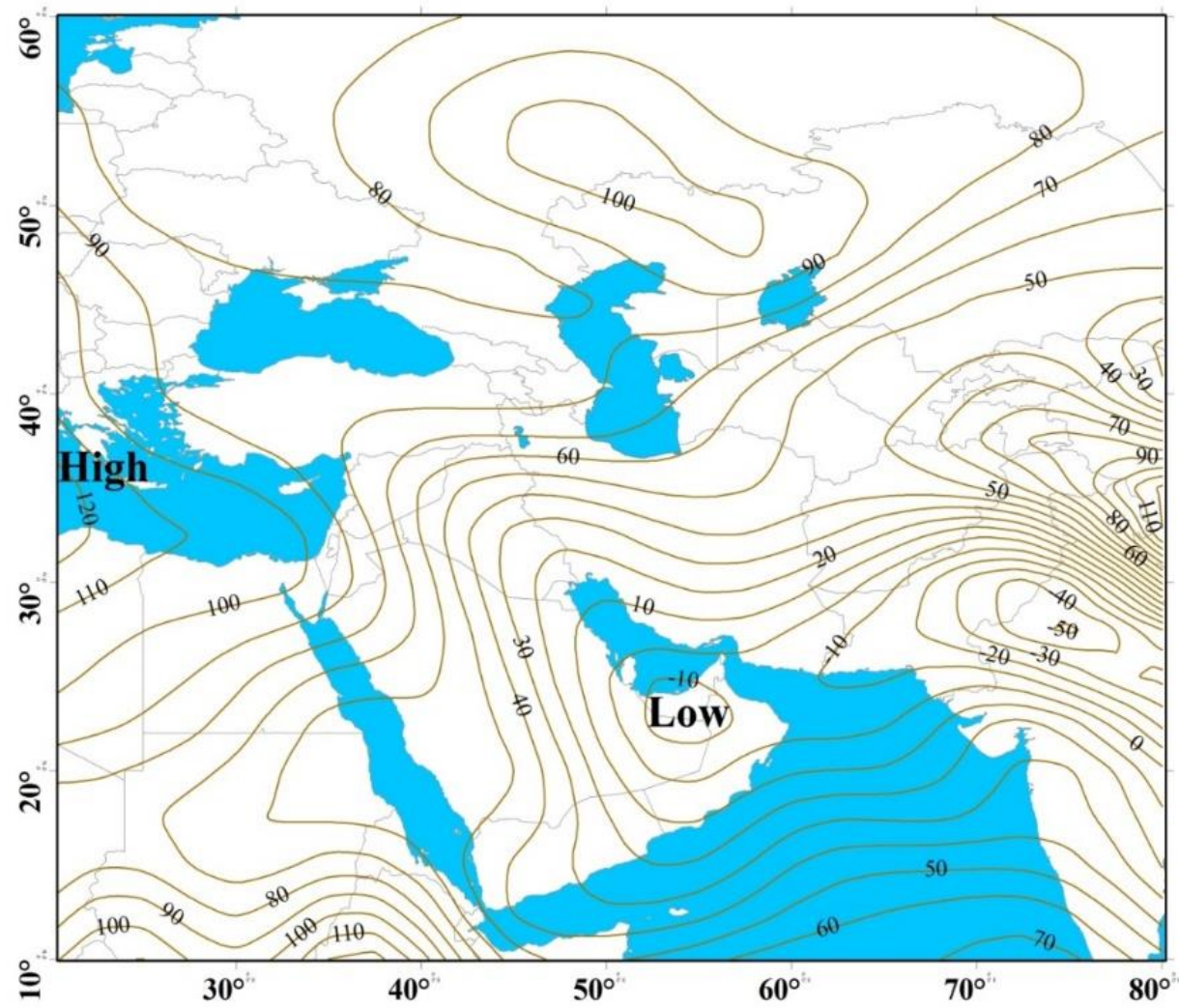

Figure 2: Average geopotential height at $1000 \mathrm{hPa}$, June to September (1948-2016).

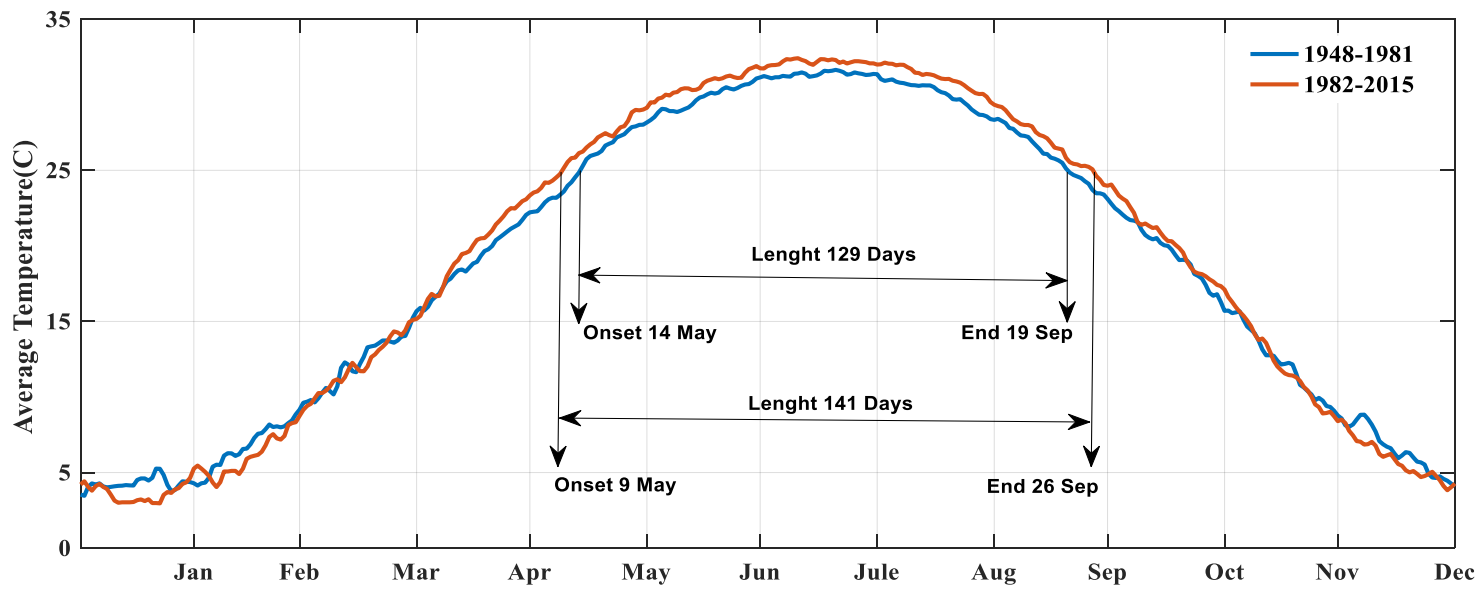

Figure 3. Onset and end dates of summer season based on physical index $\left(T>25 \mathrm{C}^{\circ}\right)$ in the defferent preiods, 19481981(blue line) and 1982-2015 (red line). 


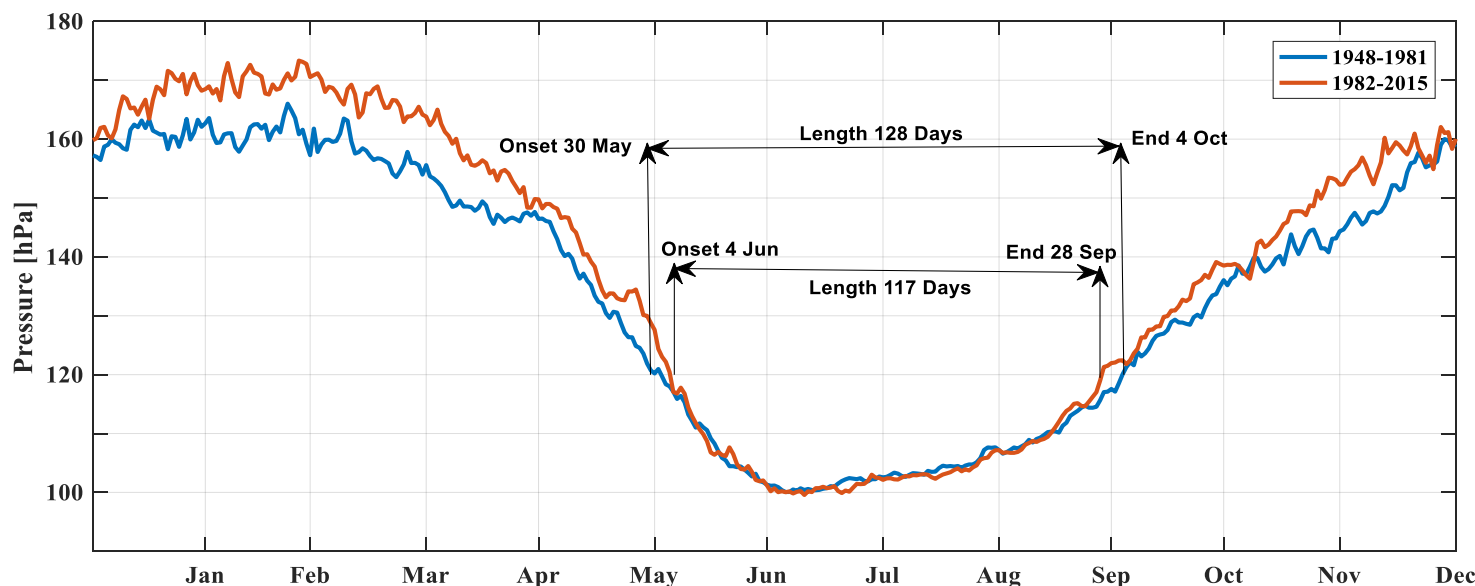

Figure 4. Onset and end dates of summer season based on daynamic index (Pressure $<120 \mathrm{hPa}$ ) in the defferent preiods, 1948-1981(blue line) and 1982-2015 (red line).

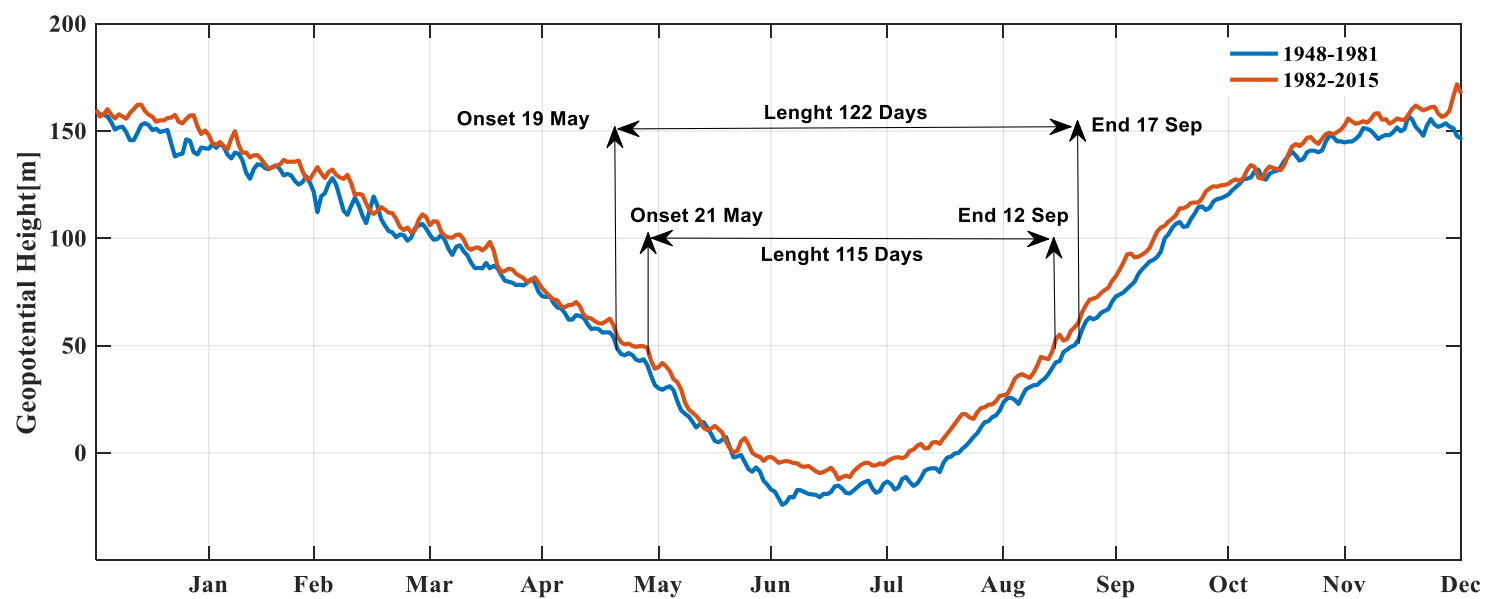

378

Figure 5. Onset and end dates of summer season based on synoptic index (Geopotential Height $<50 \mathrm{~m}$ ) in the defferent preiods, 1948-1981(blue line) and 1982-2015 (red line). 
Table 2. Average beginning and end dates and duration (in days) of summer season in the period 1948-2016

\begin{tabular}{cccc}
\hline Index aspects & Oset dates & End dates & Duration (in days) \\
\hline Physical & 11 May & 21 Sep & 134 \\
Dynamic & 4 Jun & 1 Oct & 120 \\
Synoptic & 20 May & 15 Sep & 119 \\
\hline
\end{tabular}

391

392

393

394

Table 3. The Ljung-Box Q test statistics of the onset, end and duration (in days) of summer season in the period 1948395 2016

\begin{tabular}{|c|c|c|c|c|c|}
\hline & Variable & $\mathrm{H}$ & $\mathrm{P}$ & Qstat & $\mathrm{CV}$ \\
\hline \multirow{6}{*}{ Physical } & \multirow{2}{*}{ Onset } & 1 & 0.001 & 27.32 & 24.99 \\
\hline & & 1 & 0.003 & 31.04 & 31.44 \\
\hline & \multirow{2}{*}{ End } & 1 & 0.002 & 26.05 & 24.99 \\
\hline & & 1 & 0.005 & 29.03 & 31.44 \\
\hline & \multirow{2}{*}{ Duration } & 1 & 0.001 & 34.12 & 24.99 \\
\hline & & 1 & 0.003 & 38.98 & 31.44 \\
\hline \multirow{6}{*}{ Dynamic } & \multirow{2}{*}{ Onset } & 1 & 0.03 & 27.46 & 24.99 \\
\hline & & 0 & 0.07 & 30.08 & 31.44 \\
\hline & \multirow{2}{*}{ End } & 1 & 0.06 & 25.09 & 24.99 \\
\hline & & 0 & 0.09 & 28.78 & 31.44 \\
\hline & \multirow{2}{*}{ Duration } & 1 & 0.05 & 33.17 & 24.99 \\
\hline & & 1 & 0.09 & 39.66 & 31.44 \\
\hline \multirow{6}{*}{ Synoptic } & \multirow{2}{*}{ Onset } & 1 & 0.09 & 12.56 & 24.99 \\
\hline & & 0 & 0.12 & 15.33 & 31.44 \\
\hline & \multirow{2}{*}{ End } & 1 & 0.03 & 17.87 & 24.99 \\
\hline & & 0 & 0.07 & 19.74 & 31.44 \\
\hline & \multirow{2}{*}{ Duration } & 1 & 0.003 & 13.31 & 24.99 \\
\hline & & 1 & 0.007 & 15.86 & 31.44 \\
\hline
\end{tabular}

396 
403 Table 4. Pearson correlation coefficients to determine the type and significance of the determined trends

\begin{tabular}{llllll}
\hline & Variable & $\mathrm{t}$ & $\mathrm{df}$ & $\mathrm{p}$-value & cor \\
\hline \multirow{3}{*}{ Physical } & Onset & $\mathbf{- 8 . 3 4}$ & 68 & 0.001 & -0.25 \\
& End & $\mathbf{4 . 3 2}$ & 68 & 0.001 & 0.29 \\
& Duration & $\mathbf{3 . 7 8}$ & 68 & 0.001 & 0.34 \\
\hline \multirow{3}{*}{ Dynamic } & Onset & 0.47 & 68 & 0.22 & 0.13 \\
& End & -0.23 & 68 & 0.63 & -0.04 \\
& Duration & -1.32 & 68 & 0.07 & -0.13 \\
\hline \multirow{3}{*}{ Synoptic } & Onset & 0.32 & 68 & 0.63 & 0.14 \\
& End & -0.16 & 68 & 0.82 & -0.18 \\
& Duration & -1.87 & 68 & 0.08 & -0.21 \\
\hline
\end{tabular}




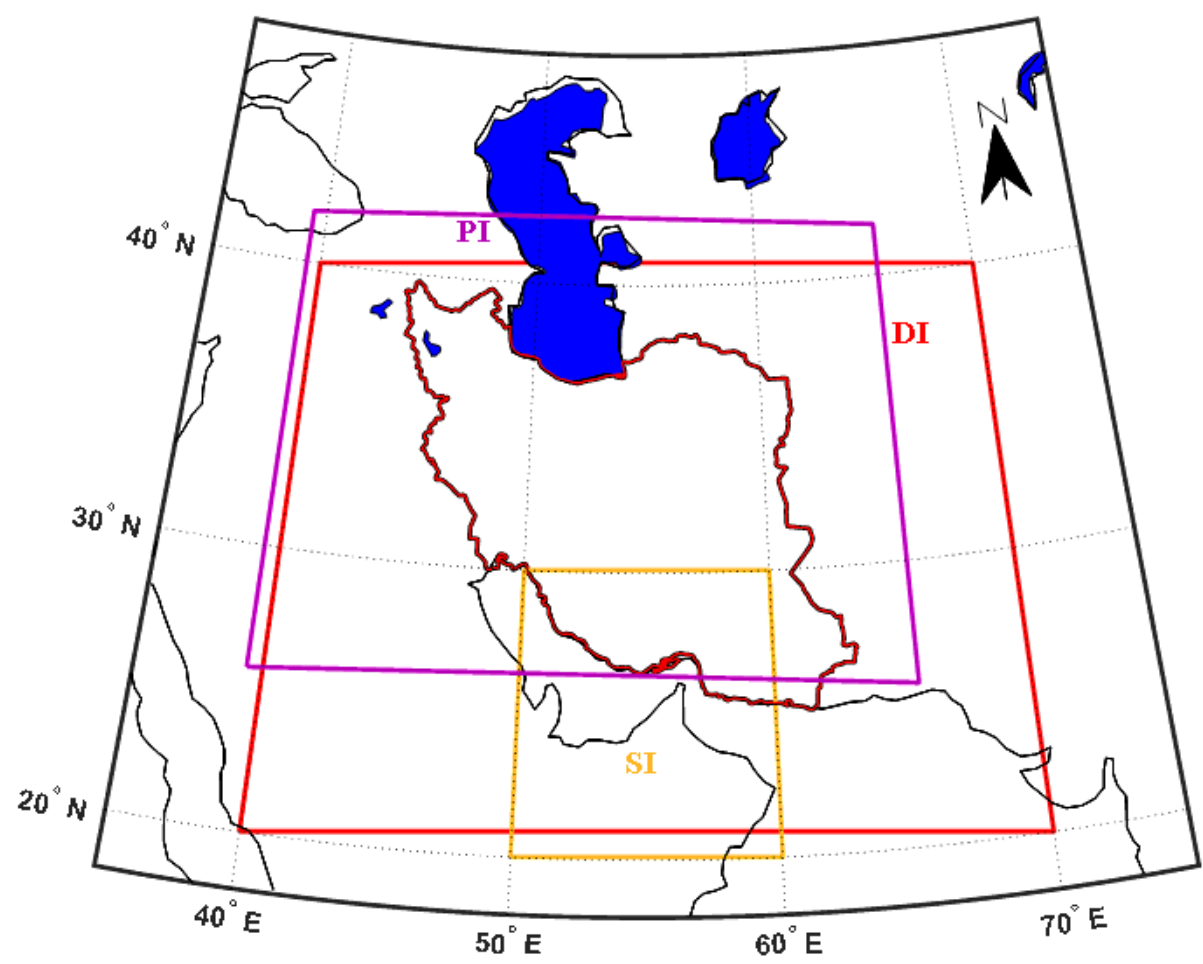

\section{Figure 1}

Geographical domains of different indicators for determining the temporal characteristics of the summer season, PI (Physical), DI (Dynamic) and SI (Synoptic). Note: The designations employed and the presentation of the material on this map do not imply the expression of any opinion whatsoever on the part of Research Square concerning the legal status of any country, territory, city or area or of its authorities, or concerning the delimitation of its frontiers or boundaries. This map has been provided by the authors. 


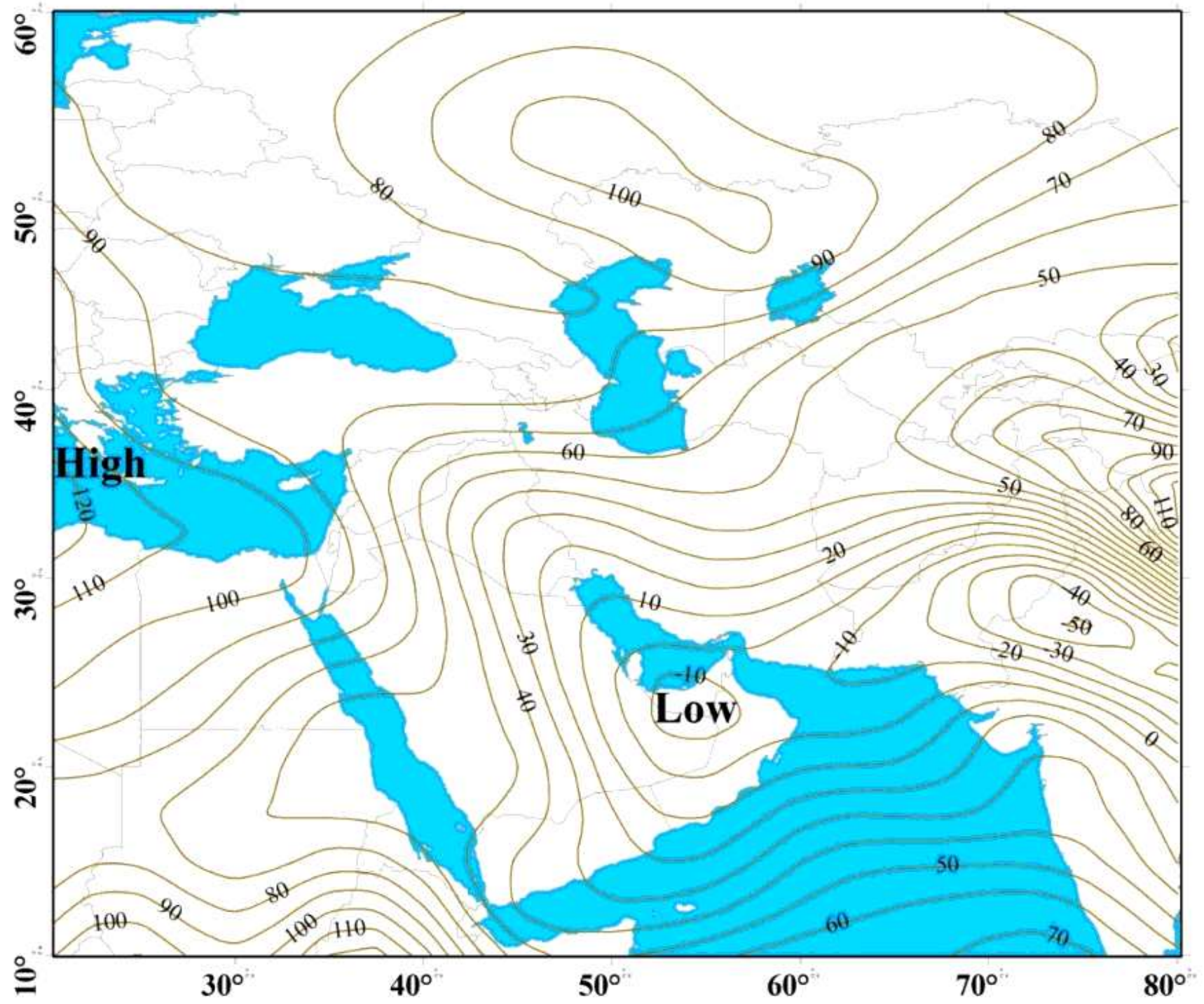

Figure 2

Average geopotential height at $1000 \mathrm{hPa}$, June to September (1948-2016). Note: The designations employed and the presentation of the material on this map do not imply the expression of any opinion whatsoever on the part of Research Square concerning the legal status of any country, territory, city or area or of its authorities, or concerning the delimitation of its frontiers or boundaries. This map has been provided by the authors. 


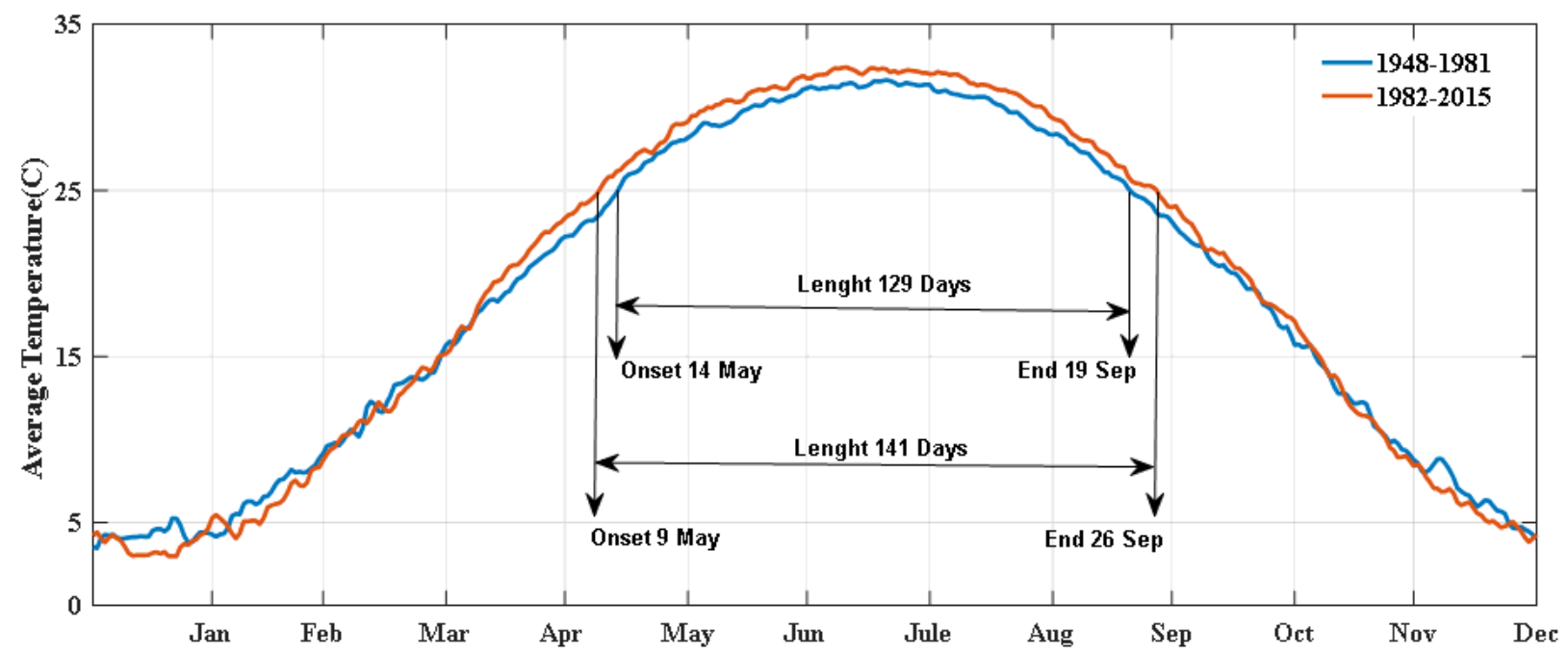

\section{Figure 3}

Onset and end dates of summer season based on physical index $\left(T>25 C^{\circ}\right)$ in the defferent preiods, 19481981 (blue line) and 1982-2015 (red line).

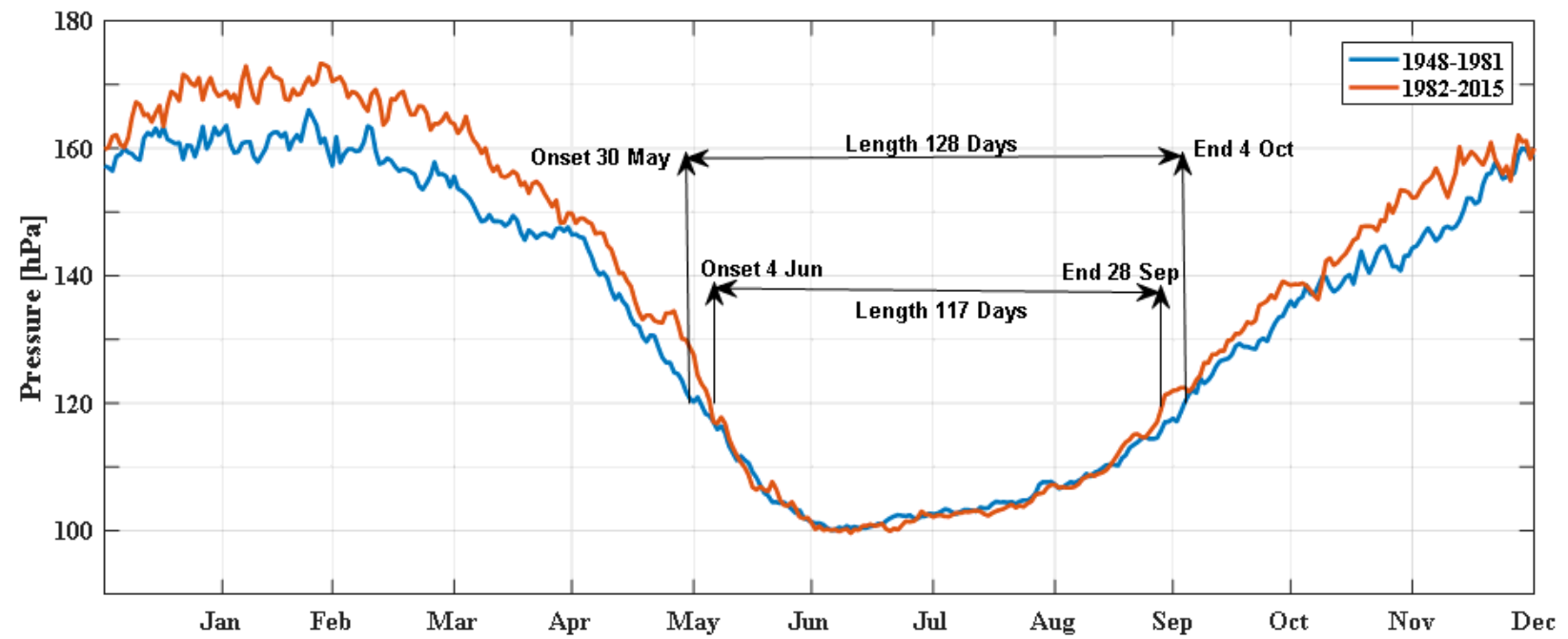

\section{Figure 4}

Onset and end dates of summer season based on daynamic index (Pressure $<120 \mathrm{hPa}$ ) in the defferent preiods, 1948-1981(blue line) and 1982-2015 (red line). 


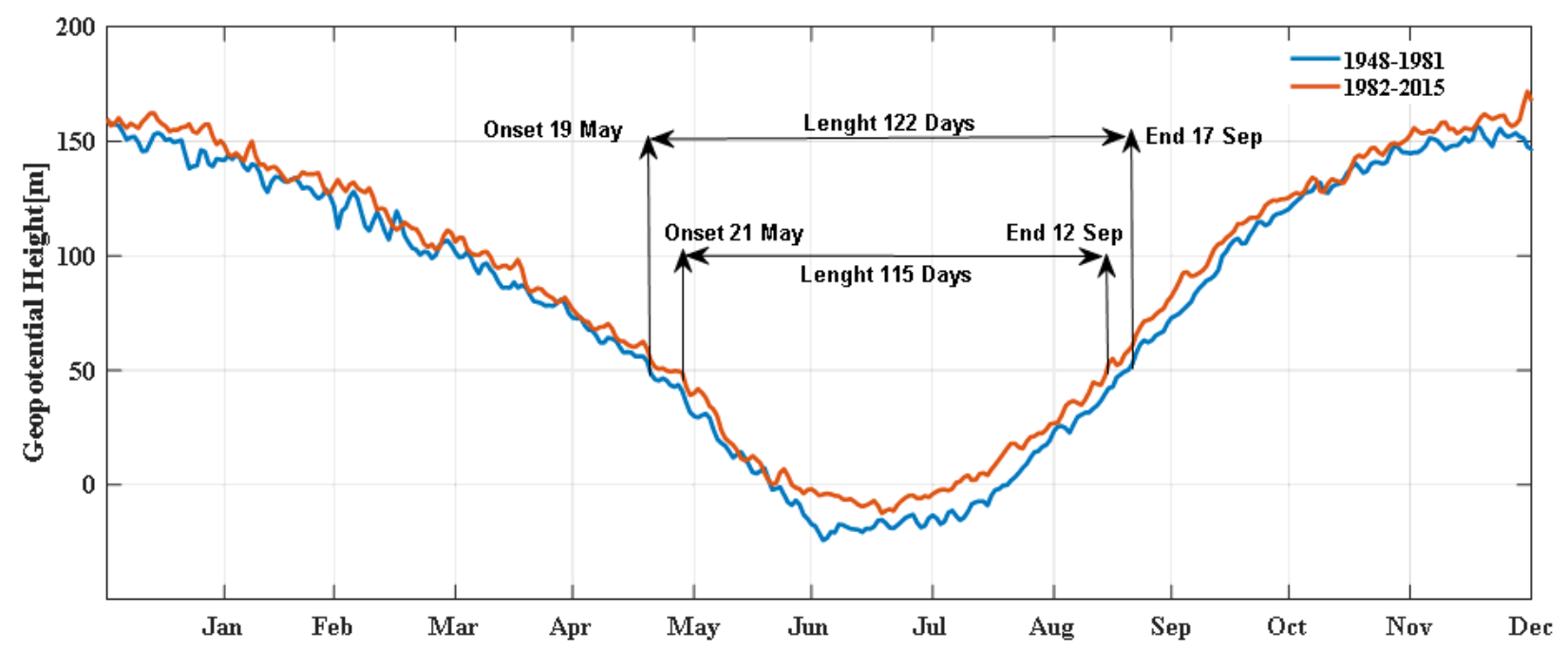

Figure 5

Onset and end dates of summer season based on synoptic index (Geopotential Height $<50 \mathrm{~m}$ ) in the defferent preiods, 1948-1981(blue line) and 1982-2015 (red line). 